\title{
Erratum to: Glocalizing' the Hijab: A Malaysian Perspective
}

\author{
Nurzihan Hassim ${ }^{1,2}$ * \\ ${ }^{1}$ Department of Media Studies, Faculty of Arts and Social Sciences, Universiti Malaya, Malaysia \\ ${ }^{2}$ School of Communication, Taylor's University, Malaysia
}

Original article:

SHS Web of Conferences 33, 00016 (2017), DOI: 10.1051/shsconf/20173300016

This erratum corrects two mistakes appearing in the original article.

1. In the title, quotation marks are missing. The title should be 'Glocalizing' the Hijab: A Malaysian perspective.

2. One affiliation of the author is missing. The affiliations should be:

${ }^{1}$ Department of Media Studies, Faculty of Arts and Social Sciences, Universiti Malaya, Malaysia

${ }^{2}$ School of Communication, Taylor's University, Malaysia 